\title{
Could age increase the strength of inverse association between ultraviolet $B$ exposure and colorectal cancer?
}

\author{
Vidya Lakshmi Purushothaman ${ }^{1,2}$, Raphael E. Cuomo ${ }^{1,2,3}$, Cedric F. Garland ${ }^{4}$ and Timothy K. Mackey ${ }^{1,2,3^{*}}$ (D)
}

\begin{abstract}
Background: Vitamin D has been identified as a potential protective factor in the development of colorectal cancer (CRC). We expect to see a stronger association of ultraviolet B (UVB) exposure and CRC crude rates with increasing age since chronic vitamin D deficiency leads to sustained molecular changes that increase cancer risk. The DINOMIT (disjunction, initiation, natural selection, overgrowth, metastasis, involution, and transition) model postulates various stages of cancer development due to vitamin D deficiency and the associated latency period. The purpose of this study is to examine this age-dependent inverse relationship globally.

Methods: In this ecological study, a series of linear and polynomial regression tests were performed between country-specific UVB estimates adjusted for cloud cover and crude incidence rates of CRC for different age groups. Multiple linear regression was used to investigate the association between crude incidence rates of colorectal cancer and UVB estimate adjusting for urbanization, skin pigmentation, smoking, animal consumption, per capita GDP, and life expectancy. Statistical analysis was followed by geospatial visualization by producing choropleth maps.
\end{abstract}

Results: The inverse relationship between UVB exposure and CRC crude rates was stronger in older age groups at the country level. Quadratic curve fitting was preferred, and these models were statistically significant for all age groups. The inverse association between crude incidence rates of CRC and UVB exposure was statistically significant for age groups above 45 years, after controlling for covariates.

Conclusion: The age-dependent inverse association between UVB exposure and incidence of colorectal cancer exhibits a greater effect size among older age groups in global analyses. Studying the effect of chronic vitamin D deficiency on colorectal cancer etiology will help in understanding the necessity for population-wide screening programs for vitamin D deficiency, especially in regions with inadequate UVB exposure. Further studies are required to assess the need for adequate public health programs such as selective supplementation and food fortification.

Keywords: Colorectal cancer, Ultraviolet B rays, UVB, Vitamin D, Aging, Crude incidence rates

\footnotetext{
* Correspondence: tmackey@ucsd.edu

${ }^{1}$ Department of Anesthesiology, University of California, San Diego, USA

${ }^{2}$ Global Health Policy Institute, San Diego, USA

Full list of author information is available at the end of the article
} 


\section{Background}

Colorectal cancer (CRC) is the third most common cancer globally with over 4 million prevalent cases. Nearly 2 million new cases of colorectal cancer were reported worldwide in 2018 [1]. It is the third most common cause of cancer in the United States with an estimated 460,714 cases in 2018 [1]. It is the second most common cause of death due to cancer worldwide and within the United States $(880,000$ deaths worldwide and fifty thousand deaths in the United States in 2018) [1]. The global burden of CRC is expected to increase by $60 \%$ to more than 2.2 million new cases and 1.1 million cancer deaths by 2030 [2]. The need for advanced prevention and treatment strategies has increased due to the need to reduce cancer morbidity and mortality for colorectal cancer.

Some of the risk factors linked to increased risk of developing CRC include obesity, sedentary lifestyle, consumption of high-fat, high-meat diets and calorie rich and fiber deficient food [3]. Apart from these known risk factors, inadequate vitamin $\mathrm{D}$ status as assessed by serum 25-hydroxyvitamin D $(25(\mathrm{OH}) \mathrm{D})$ concentration has also been identified as a potential risk factor in the pathogenesis of CRC. Vitamin D has been identified as a potential protective factor in the risk of developing CRC. Intake of $1000 \mathrm{IU} /$ day of vitamin D is shown to be associated with 50\% lower risk [4]. A meta-analysis using random effects model showed that the hazard ratio for mortality was lower with higher serum vitamin D status [5]. The results of this study suggested regular testing and restoration of vitamin $\mathrm{D}$ status to adequacy for lowering the mortality in colorectal cancer [5].

Vitamin D is a fat-soluble vitamin which has limited dietary sources and is predominantly obtained when exposed to ultraviolet B (UVB) radiation in sunlight [6]. Previtamin $\mathrm{D}_{3}$ is an intermediate product in the production of cholecalciferol. It is formed when UVB light of wavelengths between 280 and $315 \mathrm{~nm}$ from sunlight acts on 7dehydrocholesterol present in the epidermal layers of the skin. It then converts by spontaneous isomerization into cholecalciferol which is converted into the active form of vitamin D through two-step hydroxylation [6]. Availability and exposure to UVB in sunlight is strongly correlated to

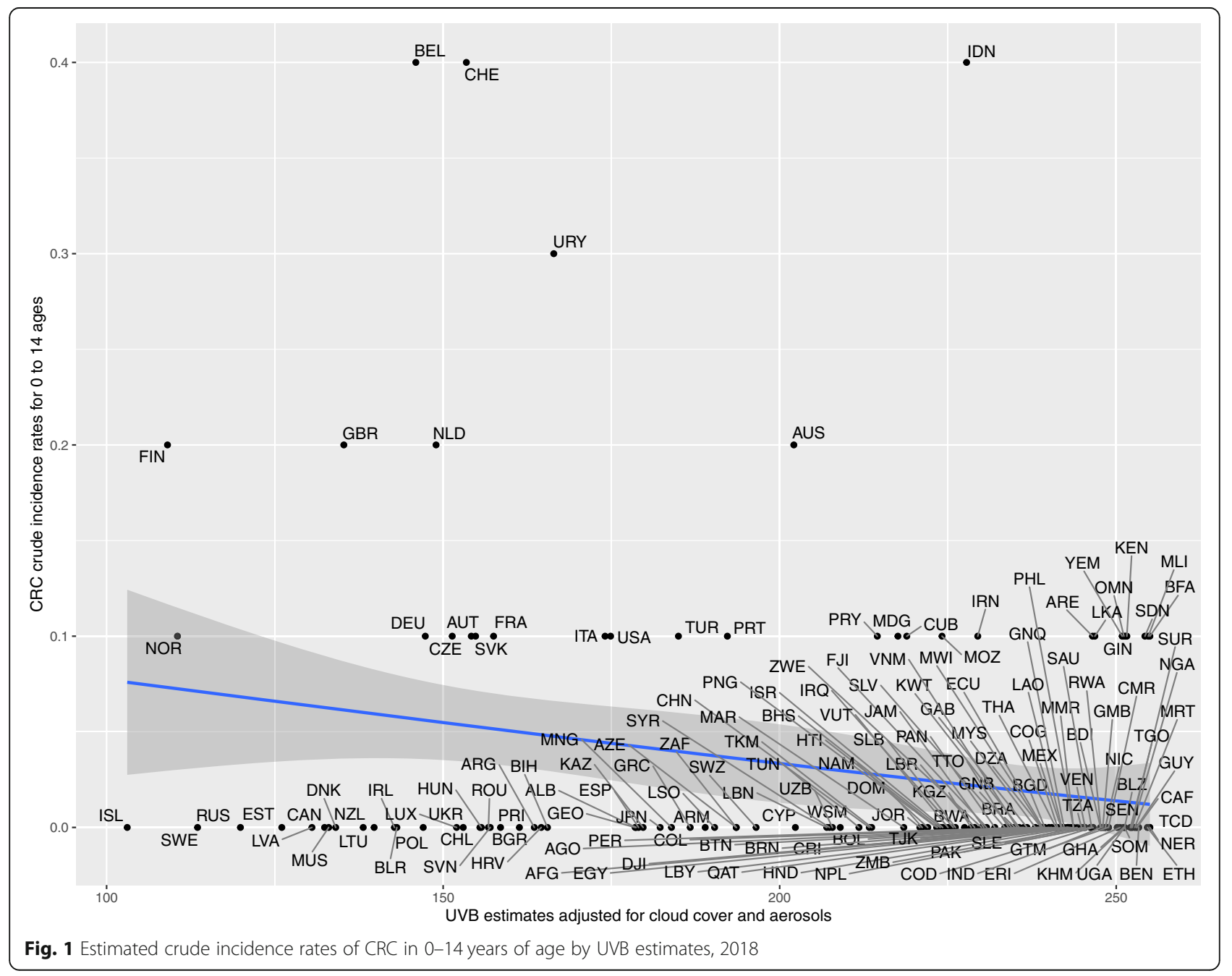


the concentration of calcidiol and calcitriol levels in blood. UVB exposure and supplemental vitamin D both increase calcitriol in a dose-dependent fashion, [7] and increases in calcitriol have been shown to depend on baseline vitamin $\mathrm{D}$ status $[8,9]$. In addition, a number of molecular factors may influence levels of serum $25(\mathrm{OH}) \mathrm{D}$, including expression of the APOE\&4 allele [10].

A recent study showed that most patients with a new diagnosis of CRC had deficient levels of serum 25(OH)D [11]. Better survival rates have been observed in patients with higher serum $25(\mathrm{OH})$ D concentrations compared to those with lower concentrations [12]. Reviews of ecological studies have shown evidence for the association between UVB-vitamin D-cancer to be convincing for several different types of cancer [13, 14]. However, not all studies have shown an increased cancer risk associated with inadequate circulating vitamin D levels. A Mendelian randomization study provided little evidence for the association of vitamin $\mathrm{D}$ and risk of several types of cancer [15].

The DINOMIT model (disjunction, initiation, natural selection, overgrowth, metastasis, involution, and transition) postulates that the anti-cancer effects of vitamin $D$ can occur across these various phases of cancer etiology [16]. Vitamin D plays a protective role in all phases by protecting intercellular gap junctions through regulation of cadherins. Tight junctions prevent cells from separating and reduce the rate of cancer progression and metastasis. The DINOMIT model also postulates the involution of cancer through replenishment of vitamin D. Vitamin D deficiency's effect on carcinogenesis is modeled as a function of time. With increasing age, the consequence of vitamin D deficiency accumulates longitudinally. Hence, the inverse epidemiological association between vitamin $\mathrm{D}$ status and incidence of colorectal cancer is expected to increase with age due to the chronicity of vitamin D deficiency. Since UVB exposure is strongly correlated to serum concentrations of $25(\mathrm{OH}) \mathrm{D}$ in the body, the strength of the inverse association between UVB estimate of a geographical area and the crude incidence rate of colorectal cancer can be studied to assess the longitudinal accumulation of carcinogenesis from vitamin $\mathrm{D}$ deficiency.

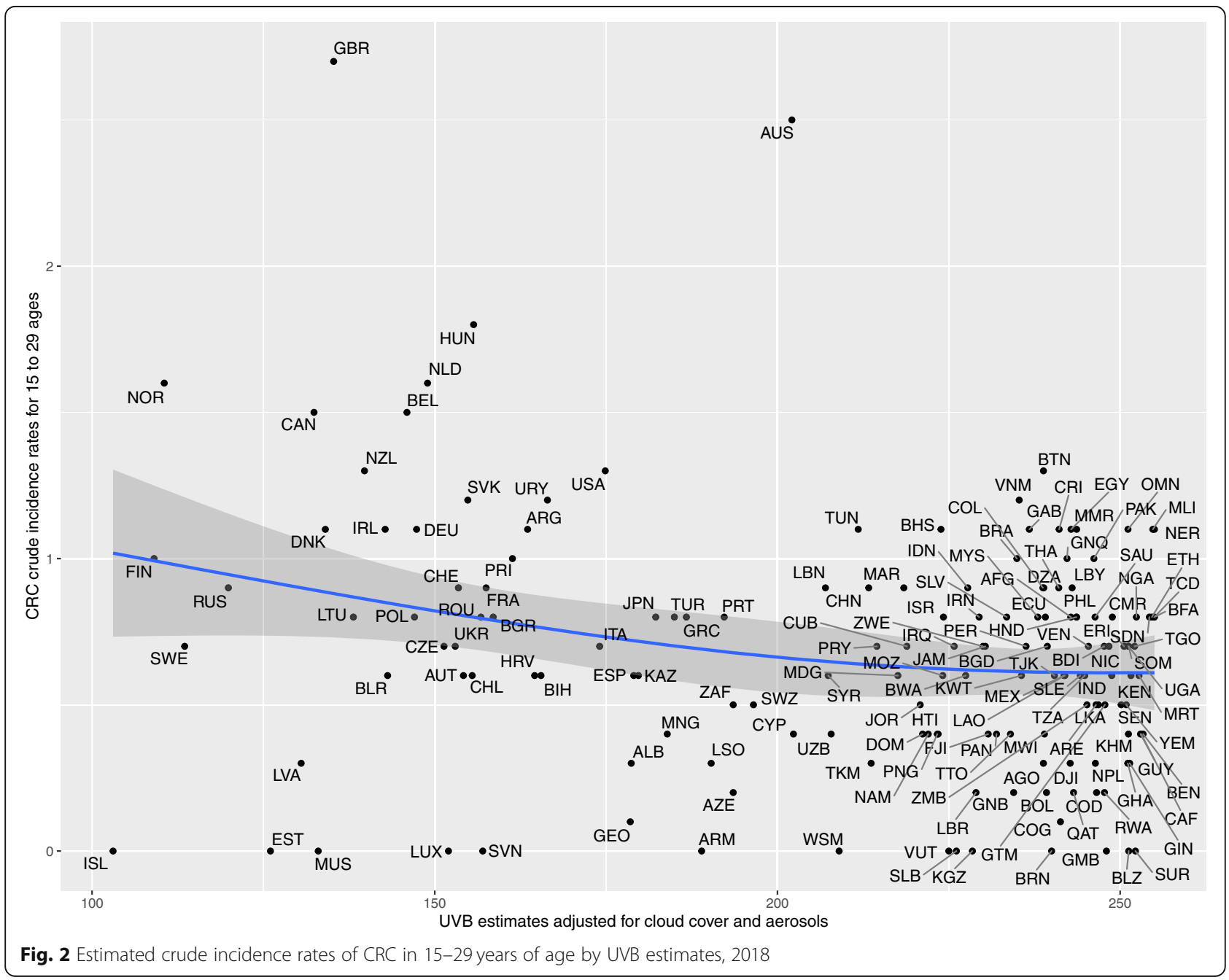


UVB exposure in a geographic area is affected by cloud cover, stratospheric ozone, altitude over sea level, skin pigmentation, number of hours spent indoors and type of clothing. Vitamin D production from UVB exposure may also be affected by air pollution and environmental chemicals [17]. Influential covariates that can affect CRC incidence include stratospheric ozone, diet, smoking prevalence, life expectancy, and wealth. The primary objective of this study to explore the effect of age on the inverse association between UVB exposure and CRC incidence, while adjusting for influential covariates. We hypothesize that the strength of the inverse association between UVB exposure and CRC incidence increases with age.

\section{Methods}

\section{Study design}

We conducted an ecological study assessing the agedependent strength of inverse relationships between cloud cover-adjusted UVB exposure and incidence of CRC globally.

\section{Data sources}

Primary outcome

The most recent age-stratified, country-specific crude rates of CRC worldwide were obtained from the Global Cancer (GLOBOCAN) database, using Cancer Today [1]. Cancer Today is a data visualization tool developed by the International Agency for Research on Cancer (IARC), a specialized cancer agency of World Health Organization (WHO). It provides estimates of the incidence, mortality, and prevalence of various cancers worldwide. Age-stratified crude incidence rates of CRC were available for 186 countries. Crude incidence rates were collected for the year 2018.

\section{Primary predictor}

Estimates for UVB (280-315 nm), adjusted for cloud cover and aerosols, were obtained from a visualization of April 2017 data from the National Aeronautics and Space Administration (NASA) EOS Aura spacecraft, available from a prior publication [18]. April was chosen as it was the closest month visualized to the spring equinox in 2017 (which occurred on March 20th). This image was processed using

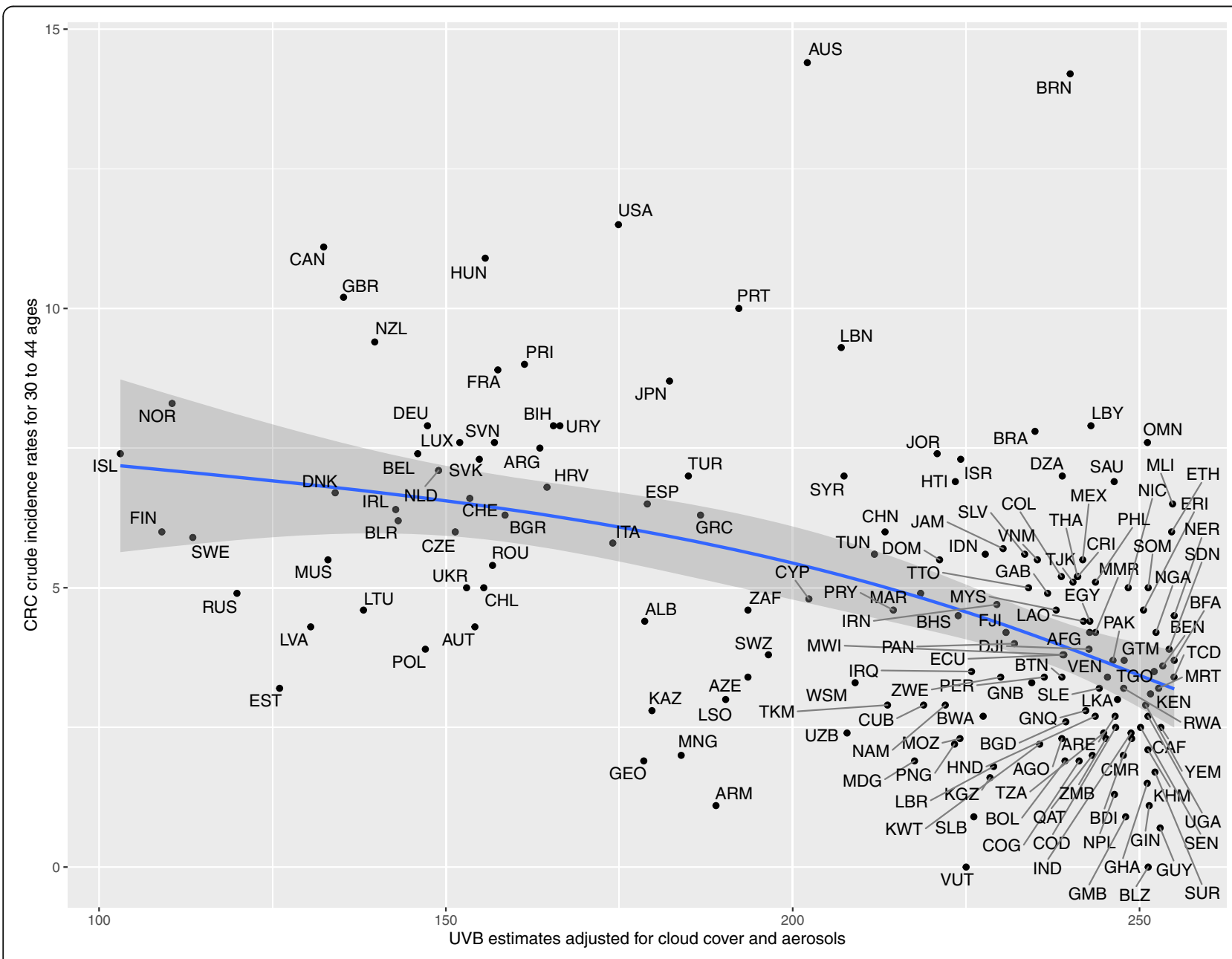

Fig. 3 Estimated crude incidence rates of CRC in 30-44 years of age by UVB estimates, 2018 
ArcGIS geospatial software to provide a mean UVB estimate for each country. Specifically, efforts were made to remove country borders, after which geospatial processing algorithms leveraged raster transformation and zonal statistics functions. The output of geoprocessing was a unitless measure of UVB between the lowest and highest possible values of 0 and 255 , respectively.

\section{Covariates}

The objective of this study is to use UVB estimates to better understand whether low levels of vitamin D may be among the risk factors for development of CRC. As a number of factors influence the development of $\mathrm{CRC}$, a wide variety of covariates were included in multiple regression analyses. Stratospheric ozone data was obtained from the NASA satellite instrument packages [19]. Data on life expectancy and GDP per capita (at purchasing power parity [PPP]) by country for those born in 2010 were provided by the World Bank [20]. GDP at PPP is nominal gross domestic product converted to international dollars using purchasing power parity rates [20]. Data on pigmentation by country was available from published literature [21]. Data on urbanization percent (urban population fraction) by country were available from a previous publication [22]. Data on smoking prevalence was collected from Global Health Data Exchange (GHDx) from the Institute for Health Metrics and Evaluation (IHME) [23]. Daily smoking prevalence was the percentage of the national population that smokes daily. Data on animal meat consumption (kilogram/capita/year) were available from the Food and Agricultural Organization of the United Nations (FAO) [24]. Data for all covariates were collected for the year 2010 (8 years prior to the incidence data).

Data for country-specific modeled serum $25(\mathrm{OH}) \mathrm{D}$ were available from a previous publication [25]. Modeling of the estimated serum $25(\mathrm{OH})$ D included measured levels of serum $25(\mathrm{OH}) \mathrm{D}$ during winter as a dependent variable, UVB irradiance was included as an independent variable and skin pigmentation as a covariate from 28 publications [25]. For countries where actual measured levels of serum $25(\mathrm{OH}) \mathrm{D}$ were not available, a prediction equation was obtained using the regression coefficients of the models for the countries with measured 25(OH) D levels [25].

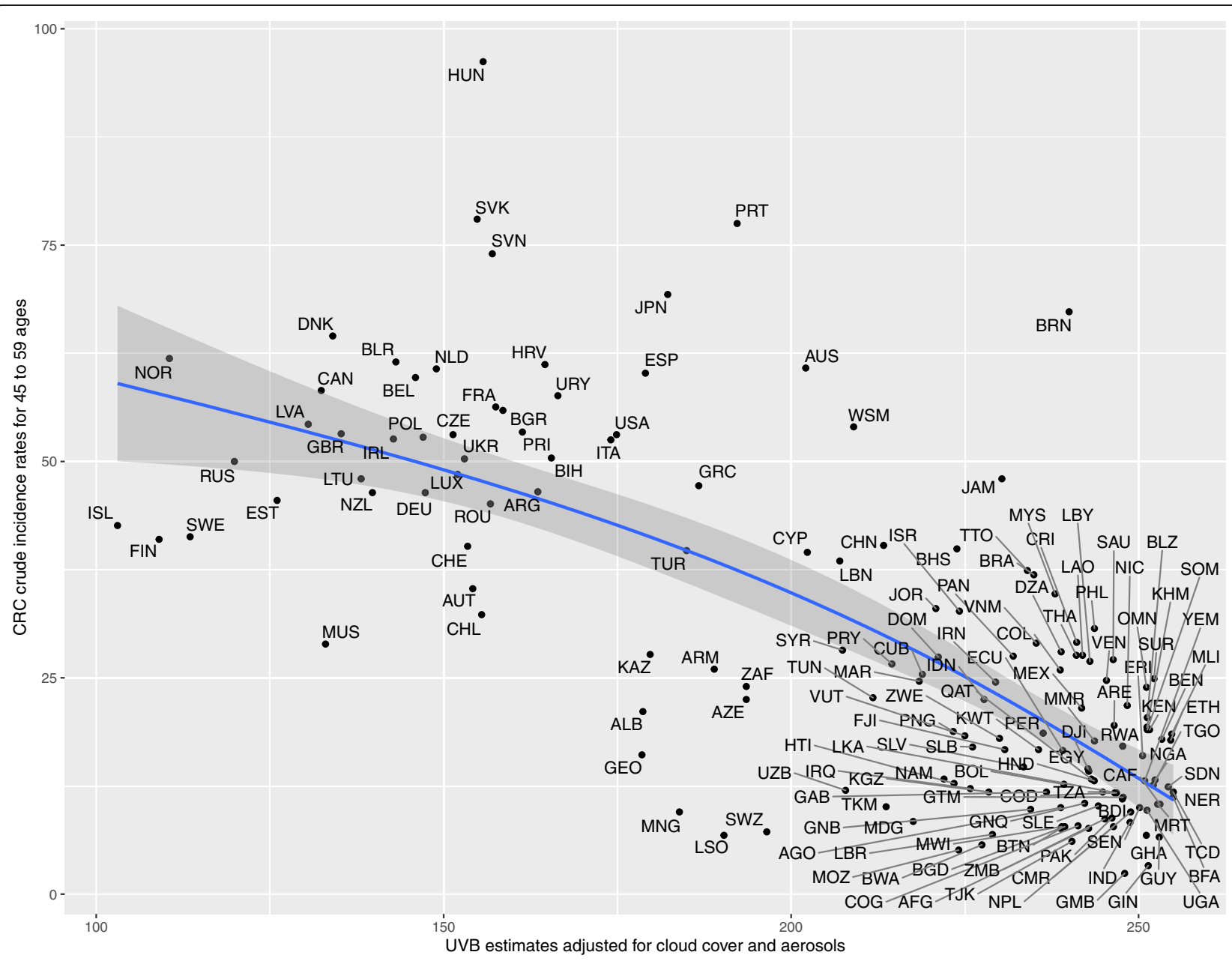

Fig. 4 Estimated crude incidence rates of CRC in 45-59 years of age by UVB estimates, 2018 


\section{Statistical analysis}

Age-stratified crude incidence rates of CRC were available for 185 countries. However, data for adjusted UVB estimates were available for only 166 countries (a list of excluded countries is provided in Appendix A). Data for all covariates were available for 148 countries. Primary statistical analyses were conducted for 166 countries and multiple linear regression was employed for 148 countries (a list of countries excluded from the multiple linear regression model is provided in Appendix B). Spearman's correlation test was used to analyze the association between adjusted UVB estimates and country-specific crude incidence rates of CRC for every age group $(0-14,15-29,30-44,45-59,60-74,>/=$ 75 years of age). A series of simple linear regression tests were performed followed by polynomial regressions between country-specific UVB estimates adjusted for cloud cover and crude incidence rates of CRC for different age groups. A better curve fit was obtained using a quadratic term. Labelled scatter plots with polynomial trend lines were plotted for each quadratic model (a list of the label codes for the names of countries (ISO 3166 standard) is provided in
Appendix C). Unadjusted quadratic models for southern hemisphere countries and northern hemisphere countries were analyzed for over 75 years of age. In addition, a subset of countries had estimates available from high-quality registry data in the IARC's CI5plus database, so a separate linear model was computed only using estimates from these countries. As sample size was relatively limited for this subanalysis, a univariate model of the relationship between UVB and crude CRC rates above age 75 was assembled.

Multiple linear regression was used to investigate the relationship between crude incidence rates of colorectal cancer and cloud cover-adjusted UVB controlling for stratospheric ozone, urbanization, skin pigmentation, smoking, animal consumption, per capita GDP, and life expectancy. A smoking covariate was also included in the age group of $0-14$ years to capture the impact of second-hand smoke on adolescents. Adjusted models for southern hemisphere countries and northern hemisphere countries were analyzed for over 75 years of age. A series of multiple linear regression models were employed to study the association between crude incidence rates of colorectal cancer and modeled

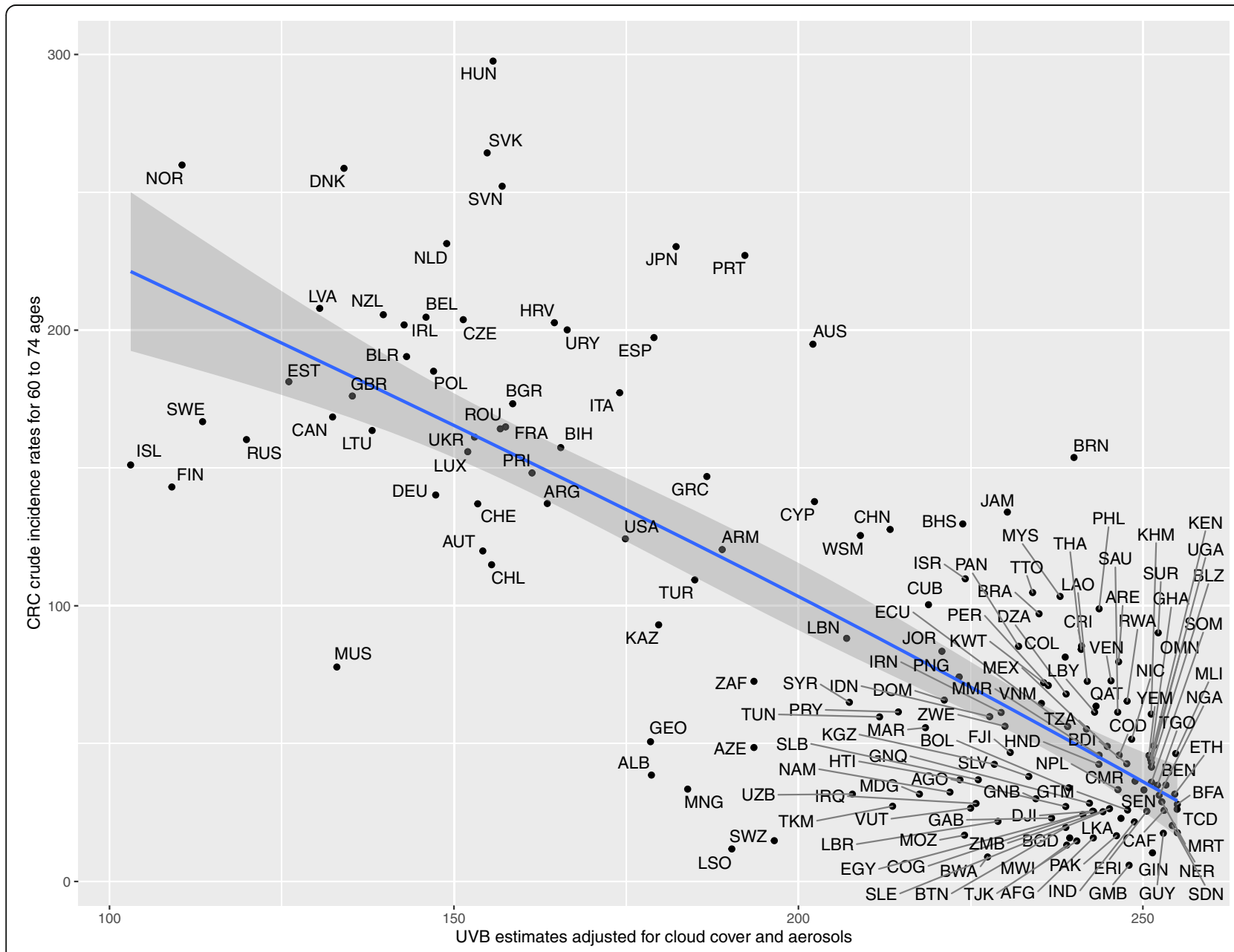

Fig. 5 Estimated crude incidence rates of CRC in 60-74 years of age by UVB estimates, 2018 


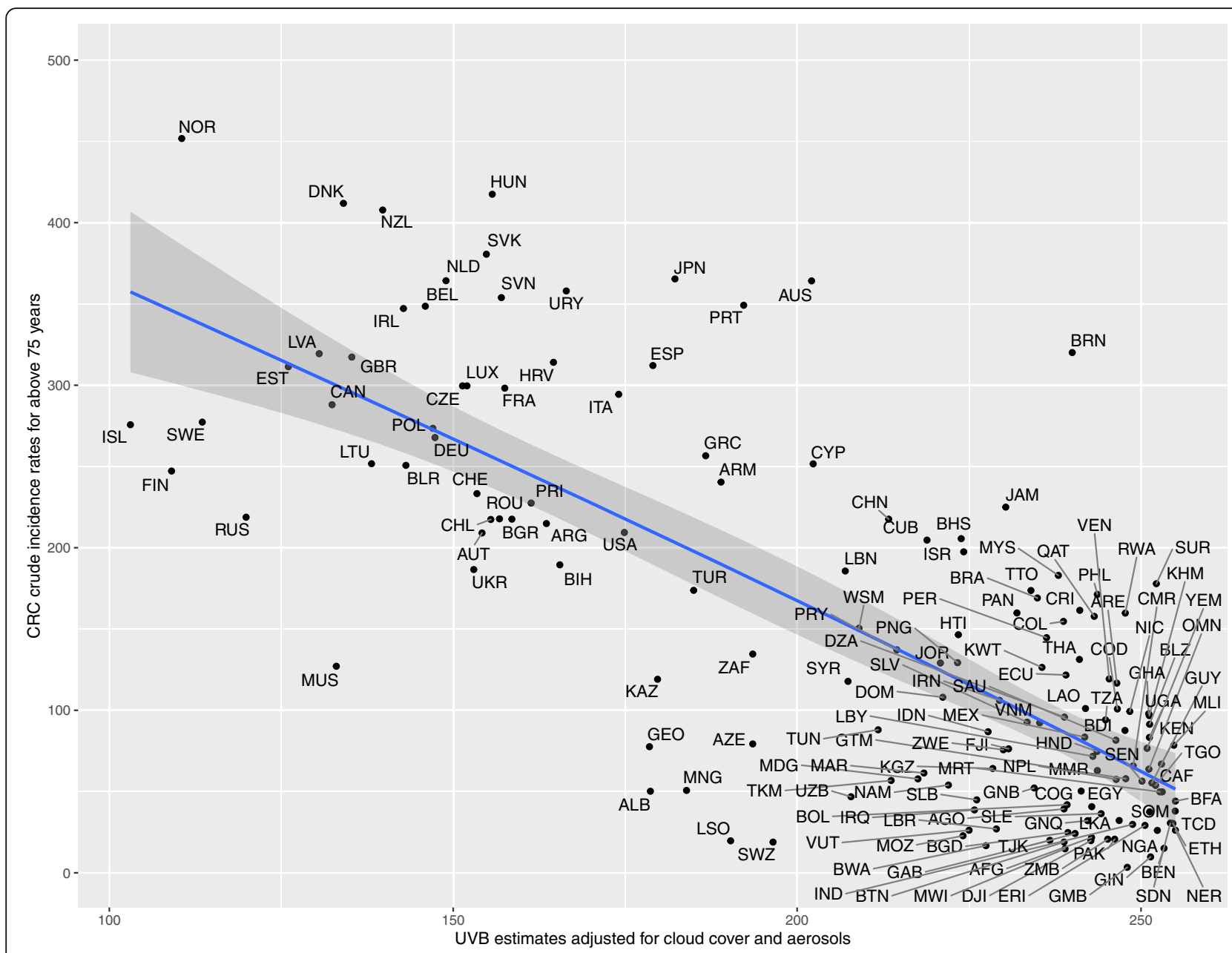

Fig. 6 Estimated crude incidence rates of CRC in >/=75 years of age by UVB estimates, 2018

25(OH) D, while controlling for urbanization, smoking, animal consumption, per capita GDP and life expectancy. UVB irradiance and skin pigmentation were taken into account in the modeled $25(\mathrm{OH}) \mathrm{D}$ values. A $p$-value of $<0.05$ was considered statistically significant for all analyses. Statistical analyses were performed using $\mathrm{R}$ version 3.6.0. Choropleth maps of country-specific CRC incidence for every age group were produced in which countries were color coded according to incidence rates. All choropleth maps were produced using QGIS software.

Table 1 Correlation between colorectal cancer crude incidence rate and ultraviolet B estimate for every age group

\begin{tabular}{lcc}
\hline Age groups & Spearman's rank correlation rho & $\boldsymbol{p}$-value \\
\hline $0-14$ years & -0.16 & 0.05 \\
15-29 years & -0.16 & 0.049 \\
30-44 years & -0.50 & $<0.001$ \\
45-59 years & -0.68 & $<0.001$ \\
$60-74$ years & -0.70 & $<0.001$ \\
$>/=75$ years & -0.69 & $<0.001$ \\
\hline
\end{tabular}

\section{Results}

Main results

Upon generating scatter plots for polynomial regression of adjusted UVB with crude incidence of CRC for each age group, an increasing trend was seen in the strength of the inverse relationship between incidence of CRC and adjusted UVB with increasing age (Figs. 1, 2, 3, 4, 5 and 6). Polynomial trend lines provided a better fit compared to linear fit trend lines. Spearman's rank correlation tests between incidence of CRC and UVB for each

Table $\mathbf{2}$ UVB estimate in association with crude incidence rate of CRC using linear regression

\begin{tabular}{lccc}
\hline Age groups & Regression Coefficient & $\boldsymbol{p}$-value & $\mathbf{R}^{\mathbf{2}}$ \\
\hline 0-14 years & $<0.001$ & 0.002 & 0.06 \\
15-29 years & -0.002 & 0.003 & 0.05 \\
30-44 years & -0.03 & $<0.001$ & 0.23 \\
45-59 years & -0.34 & $<0.001$ & 0.54 \\
60-74 years & -1.28 & $<0.001$ & 0.62 \\
$>$ /= 75 years & -2.03 & $<0.001$ & 0.59 \\
\hline
\end{tabular}


Table 3 UVB estimate in association with crude incidence rate of CRC using polynomial regression

\begin{tabular}{lcccc}
\hline $\begin{array}{l}\text { Age } \\
\text { groups }\end{array}$ & \multicolumn{2}{c}{ Regression Coefficient } & $\begin{array}{c}\text { P-value } \\
\text { (overall) }\end{array}$ & $\begin{array}{c}\mathbf{R}^{\mathbf{2}} \\
\text { (overall) }\end{array}$ \\
\cline { 2 - 3 } 0-14 years & $<0.001$ & $<0.001$ & 0.01 & 0.045 \\
15-29 years & -0.007 & $<0.001$ & 0.01 & 0.04 \\
30-44 years & 0.04 & $<0.001$ & $<0.001$ & 0.24 \\
45-59 years & 0.27 & -0.002 & $<0.001$ & 0.55 \\
60-74 years & -0.51 & -0.002 & $<0.001$ & 0.62 \\
$>$ /= 75 years & -1.78 & -0.002 & $<0.001$ & 0.58 \\
\hline
\end{tabular}

age group showed negative correlations of increasing strength with increasing age (Table 1 ).

Table 2 illustrates the results of linear regression tests between cloud cover adjusted UVB and CRC crude incidence rate for every age group.

Polynomial regression models for each age group between adjusted UVB estimates and CRC crude incidence rate showed a stronger inverse association for older age groups compared to younger age groups (Table 3). The overall $p$-value of the polynomial model was statistically significant for every age group. Also, the overall $\mathrm{R}^{2}$ of the polynomial model increased with age and the highest $R^{2}(0.62)$ was obtained for 64-75 years of age. The overall $R^{2}$ value of the polynomial model for countries in northern hemisphere for over 75 years of age was higher than that for countries in southern hemisphere before adjusting for covariates (Appendix Tables 5 and 6).

\section{Other analyses}

In the multiple linear regression model, UVB was inversely associated with crude incidence rates of colorectal cancer for all age groups above 45 years, after controlling for covariates ( $p$-value <0.05) (Table 4; Appendix Tables 7, 8, 9, 10 and 11). The highest adjusted model $R^{2}$ (0.71) was obtained for 64-75 years of age (Appendix Table 11) and over 75 years of age (Table 4). The tables for the other age groups are provided in the appendix (Appendix Tables 7, 8, 9, 10 and 11). After adjusting for covariates, the model $\mathrm{R}^{2}$ value of the polynomial model for countries in southern hemisphere for over 75 years of age was higher than that for countries in northern hemisphere (Appendix Tables 12 and 13). Also, univariate regression analysis for CRC rates above age 75, only among the 29 countries with high-quality cancer registries available from the CI5plus database, exhibited a statistically significant association with UVB $(p<0.001$; Appendix Table 14). The overall models were statistically significant with a $p$-value $<0.001$ for age groups above 45 years. The association between UVB estimates and crude incidence rates of CRC was not statistically significant in age groups below 45 years, after controlling for covariates.

According to the multiple linear regression models, the inverse association between modeled 25(OH) D and crude incidence rates of CRC was statistically significant in age groups 60-74 years, 75 years and above (Appendix Tables 15, 16, 17, 18, 19 and 20). The association was marginally significant in the age groups of 45-59 years. In age groups below 45 years, the association was not statistically significant.

Choropleth maps produced using QGIS visualized the distribution of colorectal cancer worldwide. Supplementary file Figures S1, S2, S3, S4 and S5 illustrate the distribution of CRC in different countries for every age group.

\section{Discussion}

\section{Key results}

This study aims at assessing the strength of the inverse relationship between UVB exposure and CRC incidence with increasing age. The DINOMIT model [16] proposes an explanation of how vitamin D deficiency increases the risk of developing colorectal

Table 4 UVB in association with crude incidence of CRC: over 75 years of age, controlling for covariates

\begin{tabular}{|c|c|c|c|c|}
\hline Covariate & Regression Coefficient & Standard Error & $t$ & $p$-value \\
\hline UV B estimate ${ }^{a}$ & -1.02 & 0.21 & -4.87 & $<0.001$ \\
\hline Stratospheric Ozone ${ }^{b}$ & -0.96 & 0.21 & -0.68 & 0.49 \\
\hline Urbanization $^{c}$ & 0.28 & 0.35 & 0.83 & 0.41 \\
\hline Pigmentation $^{d}$ & -15.11 & 9.83 & -1.54 & 0.13 \\
\hline GDPe & 0.001 & $<0.001$ & 2.82 & 0.006 \\
\hline Life Expectancy ${ }^{f}$ & 0.005 & 0.006 & 0.81 & 0.42 \\
\hline Smoking ${ }^{9}$ & 0.49 & 0.92 & 0.54 & 0.59 \\
\hline Animal Consumption ${ }^{\mathrm{h}}$ & 0.76 & 0.31 & 2.47 & 0.02 \\
\hline Intercept & 329.3 & 67.29 & 4.89 & $<0.001$ \\
\hline
\end{tabular}

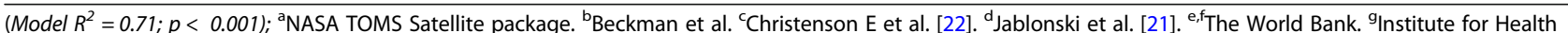
Metrics and Evaluation (IHME). ${ }^{\mathrm{h}}$ The Food and Agricultural Organization of the United Nations (FAO) 
cancer. However, it is expected to take years for these phases to occur, and hence we expect increasing age to have a major role in explaining the inverse relationship between UVB estimates and incidence of colorectal cancer. Thus, older age groups can be expected to have a stronger inverse association between vitamin D status and crude incidence rate of colorectal cancer. Though there is mixed evidence for this inverse association, our study aims at taking into consideration the effect of age on this association. In this country-specific analysis, we have shown an increasing trend in the strength of the inverse association between adjusted UVB estimates and crude incidence rate of colorectal cancer as age increases. The proportion of variability in the outcome (crude incidence rate of CRC) explained by the adjusted UVB estimate also increased with age. This study assesses the agedependent inverse association between vitamin D status and incidence of colorectal cancer globally. This is the first study to the authors' knowledge to have explored the age-related effect in this inverse association. UVB estimates decrease with increasing latitude, and higher incidence of colorectal cancer has been reported at higher latitudes [26]. Another recent study mentions low vitamin D status as a possible explanation to higher incidence rates of colon cancer in cold countries (higher latitudes) [27]. This study demonstrates a significant inverse association between UVB exposure and CRC incidence in all age groups. Age-related differences in vitamin $\mathrm{D}$ status have been observed in the regions of Asia/Pacific and Middle East/Africa [28] and reduced vitamin D status with increasing age has been reported in previous studies [29]. Also, vitamin D deficiency has been observed across all age groups globally including countries with low latitude [30]. UVB exposure is strongly correlated with serum 25(OH) D levels and previous studies have shown significant associations between $25(\mathrm{OH})$ D levels and overall CRC incidence [31]. Photosynthesized vitamin D released from erythemal solar radiation to the skin has been found to have a greater effect on serum $25(\mathrm{OH})$ D levels than dietary vitamin $\mathrm{D}$ ingestion [32]. The tissue stores of cholecalciferol which are obtained through exposure to UVB radiation help in sustaining serum $25(\mathrm{OH}) \mathrm{D}$ levels [32].

\section{Interpretation}

Previous ecological studies have reported an inverse association between UVB exposure and incidence as well as mortality of various cancers, including colon cancer [33, 34]. In one of the prior ecological studies, a significant inverse association was observed for colon cancer (among ten other cancers), and the relative risk of colon cancer incidence related to solar UVB exposure was found to be
1.11 in males and 1.14 in females [33]. In another ecological study, inverse associations with UVB were found for 15 different cancers, including colon cancer [34]. The standardized regression coefficient for age-adjusted mortality rates of colon cancer versus UVB irradiance was found to be $-0.71(p<0.001)$ for males and -0.76 $(\mathrm{p}<0.001)$ for females. However, not all ecological studies have been able to demonstrate a significant inverse association between UV exposure and colon cancer [35]. The association between UVB exposure and global incidence of colorectal cancer was first analyzed in an ecological study [26] where simple linear regression and multiple linear regression methods were used to study the inverse association between UVB exposure and incidence of CRC. In this study, the age-adjusted crude incidence rates of colorectal cancer were higher at latitudes distant from the equator $\left(R^{2}=0.50, p<0.001\right)$ [26]. In the adjusted model of that study, UVB exposure (adjusted for cloudiness) was inversely associated with age adjusted CRC crude incidence rates $(p=0.01)$, after controlling for covariates [26]. However, age-dependent strength of the inverse association between UVB exposure and colorectal cancer was not explored in that study [26].

Various studies have demonstrated the effect of diet on risk of colorectal cancer. Increased consumption of red meat and total meat were associated with higher risk of developing colorectal cancer in a study which analyzed data from a Japanese cohort [36]. Also, intake of fruits and vegetables have shown to have a protective effect against cancer [37]. Results from other studies suggest that changes in dietary pattern, specifically with increased meat consumption, can increase the risk of developing CRC [38]. A recent study observed highest number and proportion of diet-related cases for colorectal cancer [39]. Smoking is known to increase the risk of both colon and rectal cancer, with a stronger association for rectal cancer [40, 41]. The duration of smoking had a significant association with the risk of colorectal cancer [42].

A nested case-control study from the Women's Health Study (WHS) found a significant inverse association between pre-diagnostic $25(\mathrm{OH})$ D levels and risk of CRC [43]. This case-control study with 274 controls and 274 colorectal cases observed a significant inverse association between plasma vitamin $\mathrm{D}$ and odds of colorectal cancer in multivariable adjusted logistic regression models [43]. MEG3 (non-coding RNA maternally expressed gene) functions as a tumor suppressor in CRC by regulating the activity of clusterin, which is stimulated by the binding of vitamin D receptor to its promoter [44]. Metaanalysis of the relationship between serum $25(\mathrm{OH}) \mathrm{D}$ and mortality of patients with colorectal cancer has shown that higher serum $25(\mathrm{OH}) \mathrm{D}$ was associated with lower mortality of patients with colorectal cancer [5]. Mortality rates were also decreased in summertime, 
where UVB wavelengths of solar radiation are more available [45].

The main strength of this study is the novelty of assessing the age-dependent inverse relationship between UVB exposure and CRC incidence. The unadjusted analysis included 166 countries in comparison to 139 countries in a previous study [26]. The results of this analysis are in line with the previous study [26] in having obtained a significant inverse association between UVB exposure and incidence of colorectal cancer. As with prior analyses, this analysis employed multiple linear regression to account for other risk-modifying factors. UVB estimates were significantly associated with the risk of colorectal cancer in age groups over 45 years after adjusting for covariates. These findings are consistent with other studies which have found significantly different risk factors for individuals receiving a diagnosis of CRC prior to age 50, compared to those receiving a diagnosis after age 50 [46]. We suggest that several risk factors for later-age development of CRC may derive from chronic exposures, and we suggest that vitamin $\mathrm{D}$ deficiency is among these. The significant increase in the strength of this inverse association with age was observed in the analysis, as hypothesized. Also, the proportion of variation in the age-specific crude incidence rates due to UVB exposure $\left(\mathrm{R}^{2}\right)$ increased consistently with age.

\section{Limitations}

Data for all variables that were included in the multiple linear regression were available for only 148 countries out of the 185 countries for which CRC crude incidence rate data were available. However, the excluded countries account for approximately $3 \%$ of global population. Also, the inherent limitations of the data used in this study include use of neighboring country's CRC estimate in some cases of unavailability, as well as some uses of hospital-based data instead of population/registry-based data. Furthermore, countries which lacked data for UVB estimates were mostly countries with lower per capita income and limited access to healthcare, which were also closer to equator with high UVB exposure. Exclusion of these countries from the study could have reduced the strength of associations. Though laboratory research and studies on individuals have produced evidence validating the influence of UVB on serum $25(\mathrm{OH})$ $\mathrm{D}$, we note that UVB is an imperfect proxy measure of $25(\mathrm{OH})$ D status. National mean $25(\mathrm{OH})$ D concentration depends on a large number of factors. These include UVB irradiation, cloud cover, skin pigmentation, and urbanization, which are factors which were included in this study's multivariable modeling. However, additional factors, including vitamin D supplementation, clothing cover area, altitude over sea level, air pollution and environmental chemicals are also likely to be relevant, but were not included in this study due to limited availability of data or to preserve model parsimony.

\section{Generalizability}

The results of the study cannot be applied directly at the level of individuals due to ecological fallacy. However, the study findings do reveal a significant effect of age on the inverse association between UVB exposure and colorectal cancer incidence rates. The multivariate models with modeled $25(\mathrm{OH}) \mathrm{D}$ had lower $\mathrm{R}^{2}$ values compared to those with the UVB estimates adjusted for cloud cover, reducing the proportion of variability in the crude incidence of CRC explained by vitamin D levels. Also, adjusted UVB estimate was statistically significant in the age group of $45-60$ years, whereas modeled $25(\mathrm{OH}) \mathrm{D}$ was only marginally significant although both the covariates retained statistical significance in age groups above 60 years. Though our study used the modeled $25(\mathrm{OH}) \mathrm{D}$ data calculated from 28 publications, there was a mean difference of $5.26 \mathrm{nmol} / \mathrm{L}$ between the values used in the study and the published annual values of $25(\mathrm{OH}) \mathrm{D}[28,29]$.

\section{Conclusion}

Ecological studies help in generating novel, relevant hypothesis that may help in identifying causal relationships that can be further explored through studies on individuals. This study supports the need for adequate public health programs to avoid vitamin $\mathrm{D}$ inadequacy at national and global levels, whether through screening those at risk, through selective supplementation, or through populationbased measures such as food fortification. Future studies can aim at identifying the cancer types which show significant improvement with vitamin D supplementation. Studying the association between chronic vitamin D deficiency and CRC incidence will help in understanding the necessity for population-wide screening programs for vitamin D deficiency, especially in regions with inadequate UVB exposure. These programs may help decrease risk of CRC, as well as other cancers whose risk is associated with vitamin D deficiency, for high-risk populations whose vitamin D deficiency has been especially chronic.

\section{Appendix}

Table 1 UVB estimate in association with crude incidence rate of CRC using polynomial regression for countries in northern hemisphere

\begin{tabular}{lcccc}
\hline \multirow{2}{*}{$\begin{array}{l}\text { Age } \\
\text { groups }\end{array}$} & \multicolumn{2}{c}{ Regression Coefficient } & $\begin{array}{c}\text { P-value } \\
\text { (overall) }\end{array}$ & $\begin{array}{c}\mathbf{R}^{\mathbf{2}} \\
\text { (overall) }\end{array}$ \\
\cline { 2 - 3 } & UVB & UVB^2 & & \\
\hline$>/=75$ years & -0.49 & -0.004 & $<.001$ & 0.62 \\
\hline
\end{tabular}


Table 2 UVB estimate in association with crude incidence rate of CRC using polynomial regression for countries in southern hemisphere

\begin{tabular}{|c|c|c|c|c|}
\hline \multirow{2}{*}{$\begin{array}{l}\text { Age } \\
\text { groups }\end{array}$} & \multicolumn{2}{|c|}{ Regression Coefficient } & \multirow{2}{*}{$\begin{array}{l}\text { P-value } \\
\text { (overall) }\end{array}$} & \multirow{2}{*}{$\begin{array}{c}\mathrm{R}^{2} \\
\text { (overall) }\end{array}$} \\
\hline & UVB & UVB^2 & & \\
\hline$>/=75$ years & -2.26 & $<0.001$ & 0.002 & 0.36 \\
\hline
\end{tabular}

Table 3 UVB in association with crude incidence of CRC: 0-14 years of age, controlling for covariates

\begin{tabular}{|c|c|c|c|c|}
\hline Covariate & Regression Coefficient & Standard Error & $t$ & $p$-value \\
\hline UV B estimate ${ }^{a}$ & $<0.001$ & $<0.001$ & -0.74 & 0.46 \\
\hline Stratospheric Ozone ${ }^{b}$ & $<0.001$ & $<0.001$ & 3.56 & $<0.001$ \\
\hline Urbanization $^{c}$ & $<0.001$ & $<0.001$ & 0.30 & 0.77 \\
\hline Pigmentation $^{d}$ & -0.006 & 0.01 & -0.51 & 0.61 \\
\hline GDPe & $<0.001$ & $<0.001$ & 2.19 & 0.03 \\
\hline Life Expectancy $^{f}$ & $<0.001$ & $<0.001$ & 0.21 & 0.83 \\
\hline Smoking $^{g}$ & $<0.001$ & 0.001 & -0.78 & 0.43 \\
\hline Animal Consumption ${ }^{\mathrm{h}}$ & $<0.001$ & $<0.001$ & -1.48 & 0.14 \\
\hline Intercept & 0.07 & 0.08 & -0.87 & 0.39 \\
\hline
\end{tabular}

Model $R^{2}=0.15 ; p<0.001 ;{ }^{a}$ NASA TOMS Satellite package. ${ }^{\mathrm{b}}$ Beckman et al. ${ }^{\mathrm{c} C h r i s t e n s o n ~ E ~ e t ~ a l . ~[22] . ~}{ }^{\mathrm{d} J a b l o n s k i}$ et al. [21]. ${ }^{\text {ef }}$ The World Bank. ${ }^{9}$ Institute for Health

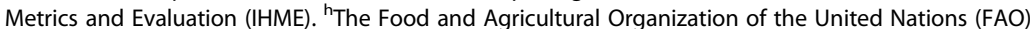

Table 4 UVB in association with crude incidence of CRC: 15-29years of age, controlling for covariates

\begin{tabular}{|c|c|c|c|c|}
\hline Covariate & Regression Coefficient & Standard Error & $t$ & $p$-value \\
\hline UV B estimate ${ }^{a}$ & 0.002 & 0.001 & 1.21 & 0.23 \\
\hline Stratospheric Ozone ${ }^{b}$ & 0.001 & $<0.001$ & 1.50 & 0.14 \\
\hline Urbanization $^{c}$ & 0.003 & 0.002 & 1.41 & 0.16 \\
\hline Pigmentation $^{d}$ & -0.23 & 0.06 & -3.46 & $<0.001$ \\
\hline GDPe & $<0.001$ & $<0.001$ & -0.60 & 0.55 \\
\hline Life Expectancy ${ }^{f}$ & $<0.001$ & $<0.001$ & -0.16 & 0.87 \\
\hline Smoking ${ }^{9}$ & -0.001 & 0.006 & -1.91 & 0.10 \\
\hline Animal Consumption ${ }^{\mathrm{h}}$ & $<0.001$ & 0.002 & 0.41 & 0.06 \\
\hline Intercept & 0.35 & 0.44 & 0.80 & 0.68 \\
\hline
\end{tabular}

d dablonski et al. [21]. e,tThe World Bank. IInstitute for Health

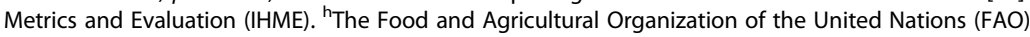


Table 5 UVB in association with crude incidence of CRC: 30-44 years of age, controlling for covariates

\begin{tabular}{|c|c|c|c|c|}
\hline Covariate & Regression Coefficient & Standard Error & $t$ & $p$-value \\
\hline UV B estimate ${ }^{a}$ & $<0.001$ & 0.007 & -0.13 & 0.90 \\
\hline Stratospheric Ozone ${ }^{\mathrm{b}}$ & 0.007 & 0.005 & 1.52 & 0.13 \\
\hline Urbanization $^{c}$ & 0.02 & 0.01 & 1.37 & 0.18 \\
\hline Pigmentation ${ }^{d}$ & -0.70 & 0.32 & -2.15 & 0.03 \\
\hline GDPe & $<0.001$ & $<0.001$ & 2.56 & 0.01 \\
\hline Life Expectancy ${ }^{f}$ & $<0.001$ & $<0.001$ & 0.53 & 0.60 \\
\hline Smoking $^{9}$ & -0.03 & 0.03 & -1.27 & 0.21 \\
\hline Animal Consumption ${ }^{\mathrm{h}}$ & 0.01 & 0.01 & 1.13 & 0.26 \\
\hline Intercept & 2.85 & 2.17 & 1.31 & 0.19 \\
\hline
\end{tabular}

Model $R^{2}=0.42 ; p<0.001$; ${ }^{a}$ NASA TOMS Satellite package. ${ }^{b}$ Beckman et al. ${ }^{\mathrm{c} C h r i s t e n s o n ~ E ~ e t ~ a l . ~[22] . ~}{ }^{\mathrm{d}}$ Jablonski et al. [21]. ${ }^{\text {e,f }}$ The World Bank. ${ }^{9}$ Institute for Health Metrics and Evaluation (IHME). ${ }^{\text {h}}$ The Food and Agricultural Organization of the United Nations (FAO)

Table 6 UVB in association with crude incidence of CRC: 45-59 years of age, controlling for covariates

\begin{tabular}{|c|c|c|c|c|}
\hline Covariate & Regression Coefficient & Standard Error & $t$ & $p$-value \\
\hline UV B estimate ${ }^{a}$ & -0.14 & 0.04 & -3.52 & $<0.001$ \\
\hline Stratospheric Ozone ${ }^{b}$ & 0.01 & 0.03 & 0.39 & 0.70 \\
\hline Urbanization $^{c}$ & -0.01 & 0.07 & -0.17 & 0.86 \\
\hline Pigmentation $^{d}$ & -2.14 & 1.83 & -1.17 & 0.24 \\
\hline GDPe & $<0.001$ & $<0.001$ & 1.88 & 0.06 \\
\hline Life Expectancy ${ }^{f}$ & 0.002 & 0.001 & 1.52 & 0.13 \\
\hline Smoking ${ }^{9}$ & 0.37 & 0.17 & 2.16 & 0.03 \\
\hline Animal Consumption ${ }^{h}$ & 0.20 & 0.06 & 3.42 & $<0.001$ \\
\hline Intercept & 40.76 & 12.55 & 3.25 & 0.002 \\
\hline
\end{tabular}

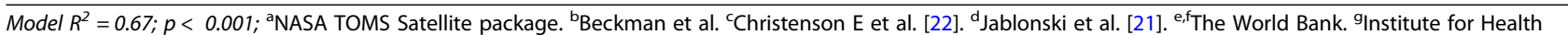
Metrics and Evaluation (IHME). ${ }^{\text {h }}$ The Food and Agricultural Organization of the United Nations (FAO)

Table 7 UVB in association with crude incidence of CRC: 60-74 years of age, controlling for covariates

\begin{tabular}{|c|c|c|c|c|}
\hline Covariate & Regression Coefficient & Standard Error & $t$ & $\overline{p \text {-value }}$ \\
\hline UV B estimate $^{a}$ & -0.69 & 0.13 & -5.35 & $<0.001$ \\
\hline Stratospheric Ozone ${ }^{\mathrm{b}}$ & -0.02 & 0.09 & -0.19 & 0.85 \\
\hline Urbanization $^{c}$ & 0.05 & 0.22 & 0.23 & 0.82 \\
\hline Pigmentation $^{\mathrm{d}}$ & -7.84 & 6.05 & -1.29 & 0.20 \\
\hline GDPe & $<0.001$ & $<0.001$ & 1.97 & 0.051 \\
\hline Life Expectancy ${ }^{f}$ & 0.004 & 0.004 & 0.10 & 0.33 \\
\hline Smoking $^{g}$ & 0.95 & 0.57 & 1.67 & 0.10 \\
\hline Animal Consumption ${ }^{\mathrm{h}}$ & 0.48 & 0.19 & 2.52 & 0.01 \\
\hline Intercept & 200.9 & 41.45 & 4.85 & $<0.001$ \\
\hline
\end{tabular}

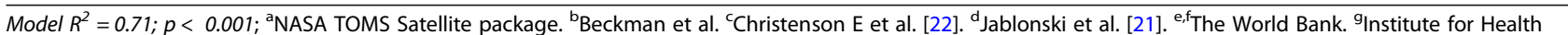
Metrics and Evaluation (IHME). ${ }^{\text {h }}$ The Food and Agricultural Organization of the United Nations (FAO) 
Table 8 UVB in association with crude incidence of CRC: over 75 years of age for countries in northern hemisphere after controlling for covariates

\begin{tabular}{|c|c|c|c|c|}
\hline Covariate & Regression Coefficient & Standard Error & $t$ & $p$-value \\
\hline UV B estimate ${ }^{a}$ & -1.43 & 0.25 & -5.62 & $<0.001$ \\
\hline Stratospheric Ozone ${ }^{\mathrm{b}}$ & -0.10 & 0.15 & -0.67 & 0.51 \\
\hline Urbanization $^{c}$ & 0.10 & 0.38 & 0.26 & 0.80 \\
\hline Pigmentation $^{d}$ & 12.94 & 12.53 & 1.03 & 0.30 \\
\hline GDPe & 0.002 & $<0.001$ & 3.10 & 0.003 \\
\hline Life Expectancy ${ }^{f}$ & 0.009 & 0.008 & 1.11 & 0.27 \\
\hline Smoking $^{g}$ & 1.41 & 0.95 & 1.50 & 0.14 \\
\hline Animal Consumption ${ }^{\mathrm{h}}$ & 0.83 & 0.32 & 2.57 & 0.01 \\
\hline Intercept & 359.70 & 71.06 & 5.06 & $<0.001$ \\
\hline
\end{tabular}

Model $R^{2}=0.72 ; p<0.001 ;{ }^{a}$ NASA TOMS Satellite package. ${ }^{b}$ Beckman et al. ${ }^{c}$ Christenson E et al. [22]. ${ }^{d}$ Jablonski et al. [21]. ${ }^{\text {eff }}$ The World Bank. ${ }^{9}$ Institute for Health

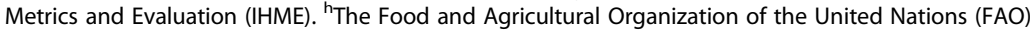

Table 9 UVB in association with crude incidence of CRC: over 75 years of age for countries in southern hemisphere after controlling for covariates

\begin{tabular}{|c|c|c|c|c|}
\hline Covariate & Regression Coefficient & Standard Error & $t$ & $p$-value \\
\hline UV B estimate ${ }^{a}$ & -1.18 & 0.47 & -2.52 & 0.02 \\
\hline Stratospheric Ozone ${ }^{\mathrm{b}}$ & 0.57 & 0.36 & 1.59 & 0.13 \\
\hline Urbanization $^{c}$ & 0.53 & 0.78 & 0.67 & 0.51 \\
\hline Pigmentation $^{\mathrm{d}}$ & -89.49 & 24.56 & -3.64 & 0.002 \\
\hline GDPe & 0.002 & 0.003 & 0.82 & 0.43 \\
\hline Life Expectancy ${ }^{f}$ & 0.02 & 0.01 & 1.73 & 0.10 \\
\hline Smoking ${ }^{g}$ & -3.53 & 2.64 & -1.34 & 0.20 \\
\hline Animal Consumption ${ }^{h}$ & -0.82 & 1.02 & -0.81 & 0.43 \\
\hline Intercept & 475.41 & 179.95 & 2.54 & 0.02 \\
\hline
\end{tabular}

Model $R^{2}=0.81 ; p<0.001 ;{ }^{a}$ NASA TOMS Satellite package. ${ }^{b}$ Beckman et al. ${ }^{C}$ Christenson E et al. [22]. ${ }^{d}$ Jablonski et al. [21]. ${ }^{\text {ef }}$ The World Bank. ${ }^{9}$ Institute for Health

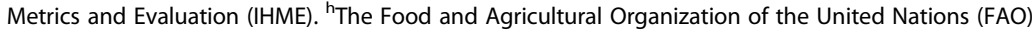

Table 10 UVB estimate in association with crude incidence rate of CRC using linear regression among countries with highquality registry data in the $\mathrm{Cl} 5$ plus database

\begin{tabular}{lccc}
\hline Age groups & Regression Coefficient & $\boldsymbol{p}$-value & $\mathbf{R}^{\mathbf{2}}$ \\
\hline$>/=75$ years & -1.36 & $<0.001$ & 0.35 \\
\hline
\end{tabular}

Table 11 Modeled 25(OH) D in association with incidence of CRC in 0-14 years of age, controlling for covariates

\begin{tabular}{|c|c|c|c|c|}
\hline Covariate & $\begin{array}{l}\text { Regression } \\
\text { Coefficient }\end{array}$ & $\begin{array}{l}\text { Standard } \\
\text { Error }\end{array}$ & $t$ & $\begin{array}{c}p- \\
\text { value }\end{array}$ \\
\hline $\begin{array}{l}\text { Modeled 25(OH) D, } \\
\mathrm{ng} / \mathrm{ml}^{\mathrm{a}}\end{array}$ & $<0.001$ & $<0.001$ & -0.49 & 0.63 \\
\hline Urbanization $^{\text {b }}$ & $<0.001$ & $<0.001$ & 0.53 & 0.60 \\
\hline $\mathrm{GDP}^{\mathrm{C}}$ & $<0.001$ & $<0.001$ & 2.84 & 0.005 \\
\hline Life Expectancy $^{d}$ & $<0.001$ & $<0.001$ & -0.07 & 0.95 \\
\hline Smokinge & $<0.001$ & 0.001 & 0.51 & 0.61 \\
\hline $\begin{array}{l}\text { Animal } \\
\text { Consumption }^{f}\end{array}$ & $<0.001$ & $<0.001$ & -1.54 & 0.13 \\
\hline Intercept & 0.02 & 0.04 & 0.50 & 0.62 \\
\hline \multicolumn{5}{|c|}{$\begin{array}{l}\text { Model } R^{2}=0.06 ; p=0.02 ;{ }^{a} \text { Mohr S, B, Gorham E, D, Garland C, F, Grant W, B, } \\
\text { Garland F, C: Low Ultraviolet B and Increased Risk of Brain Cancer: An } \\
\text { Ecological Study of } 175 \text { Countries. Neuroepidemiology 2010; 35:281-290. doi: } \\
\text { https://doi.org/10.1159/000314350. }{ }^{\mathrm{b}} \text { Christenson E et al. [22]. }{ }^{c, d} \text { The World } \\
\text { Bank. 'Institute for Health Metrics and Evaluation (IHME). }{ }^{\text {T }} \text { The Food and } \\
\text { Agricultural Organization of the United Nations (FAO) }\end{array}$} \\
\hline
\end{tabular}


Table 12 Modeled 25(OH) D in association with incidence of CRC in 15-29years of age, controlling for covariates

\begin{tabular}{|c|c|c|c|c|}
\hline Covariate & Regression Coefficient & Standard Error & $t$ & $p$-value \\
\hline Modeled 25(OH) D, ng/mla & -0.004 & 0.004 & -1.16 & 0.25 \\
\hline Urbanization $^{\mathrm{b}}$ & 0.005 & 0.002 & 2.01 & 0.046 \\
\hline GDPc & $<0.001$ & $<0.001$ & 0.26 & 0.79 \\
\hline Life Expectancy ${ }^{d}$ & $<0.001$ & $<0.001$ & -0.39 & 0.69 \\
\hline Smoking ${ }^{e}$ & -0.003 & 0.006 & -0.58 & 0.56 \\
\hline Animal Consumption ${ }^{f}$ & $<0.001$ & 0.002 & 0.37 & 0.71 \\
\hline Intercept & 0.58 & 0.25 & 2.29 & 0.02 \\
\hline
\end{tabular}

Model $R^{2}=0.10 ; p=0.002 ;{ }^{a}$ Mohr S, B, Gorham E, D, Garland C, F, Grant W, B, Garland F, C: Low Ultraviolet B and Increased Risk of Brain Cancer: An Ecological Study of 175 Countries. Neuroepidemiology 2010; 35:281-290. doi: https://doi.org/10.1159/000314350. ${ }^{b}$ Christenson E et al. [22]. ${ }^{c, d}$ The World Bank. ${ }^{e}$ Institute for Health Metrics and Evaluation (IHME). ${ }^{\mathrm{f}}$ The Food and Agricultural Organization of the United Nations (FAO)

Table 13 Modeled 25(OH) D in association with incidence of CRC in 30-44 years of age, controlling for covariates

\begin{tabular}{|c|c|c|c|c|}
\hline Covariate & Regression Coefficient & Standard Error & $t$ & $p$-value \\
\hline Modeled 25(OH) D, ng/mla & -0.02 & 0.02 & -1.23 & 0.22 \\
\hline Urbanization $^{\mathrm{b}}$ & 0.02 & 0.01 & 1.63 & 0.11 \\
\hline $\mathrm{GDP}^{\mathrm{C}}$ & $<0.001$ & $<0.001$ & 3.20 & 0.002 \\
\hline Life Expectancy ${ }^{d}$ & $<0.001$ & $<0.001$ & 0.25 & 0.80 \\
\hline Smoking ${ }^{e}$ & $<0.001$ & 0.03 & 0.03 & 0.98 \\
\hline Animal Consumption ${ }^{f}$ & 0.01 & 0.01 & 1.15 & 0.25 \\
\hline Intercept & 3.14 & 1.25 & 2.52 & 0.01 \\
\hline
\end{tabular}

Table 14 Modeled 25(OH) D in association with incidence of CRC in 45-59years of age, controlling for covariates

\begin{tabular}{|c|c|c|c|c|}
\hline Covariate & Regression Coefficient & Standard Error & $t$ & $p$-value \\
\hline Modeled 25(OH) D, ng/m/ ${ }^{a}$ & -0.23 & 0.12 & -1.92 & 0.06 \\
\hline Urbanization $^{b}$ & -0.02 & 0.07 & -0.32 & 0.75 \\
\hline$G D P^{c}$ & $<0.001$ & $<0.001$ & 2.05 & 0.04 \\
\hline Life Expectancy ${ }^{d}$ & 0.001 & 0.001 & 0.74 & 0.46 \\
\hline Smoking ${ }^{e}$ & 0.60 & 0.19 & 3.16 & 0.002 \\
\hline Animal Consumption ${ }^{f}$ & 0.29 & 0.06 & 4.57 & $<0.001$ \\
\hline Intercept & 11.51 & 7.93 & 1.45 & 0.15 \\
\hline
\end{tabular}

Model $R^{2}=0.58 ; p<0.001 ;{ }^{a}$ Mohr S, B, Gorham E, D, Garland C, F, Grant W, B, Garland F, C: Low Ultraviolet B and Increased Risk of Brain Cancer: An Ecological Study of 175 Countries. Neuroepidemiology 2010; 35:281-290. doi: https://doi.org/10.1159/000314350. ${ }^{b}$ Christenson E et al. [22]. c,d The World Bank. Institute for Health Metrics and Evaluation (IHME). ${ }^{f}$ The Food and Agricultural Organization of the United Nations (FAO) 
Table 15 Modeled 25(OH) D in association with incidence of CRC in 60-74 years of age, controlling for covariates

\begin{tabular}{|c|c|c|c|c|}
\hline Covariate & Regression Coefficient & Standard Error & $t$ & $p$-value \\
\hline Modeled 25(OH) D, ng/ml ${ }^{a}$ & -1.30 & 0.40 & -3.28 & 0.001 \\
\hline Urbanization $^{\mathrm{b}}$ & 0.04 & 0.25 & 0.17 & 0.87 \\
\hline$G^{c} P^{c}$ & 0.001 & $<0.001$ & 2.12 & 0.04 \\
\hline Life Expectancy ${ }^{d}$ & 0.001 & 0.005 & 0.19 & 0.85 \\
\hline Smokinge & 1.73 & 0.63 & 2.74 & 0.007 \\
\hline Animal Consumption ${ }^{f}$ & 0.86 & 0.21 & 4.09 & $<0.001$ \\
\hline Intercept & 52.72 & 26.52 & 1.98 & 0.048 \\
\hline
\end{tabular}

Model $R^{2}=0.61 ; p<0.001$; ${ }^{a}$ Mohr S, B, Gorham E, D, Garland C, F, Grant W, B, Garland F, C: Low Ultraviolet B and Increased Risk of Brain Cancer: An Ecological Study of 175 Countries. Neuroepidemiology 2010; 35:281-290. doi: https://doi.org/10.1159/000314350. ${ }^{b}$ Christenson E et al. [22]. ${ }^{c, d}$ The World Bank. ${ }^{e}$ Institute for Health Metrics and Evaluation (IHME). ${ }^{\mathrm{f}}$ The Food and Agricultural Organization of the United Nations (FAO)

\section{Appendix A}

\section{List of excluded countries for which UVB estimates were} unavailable

1. Cabo Verde

2. Côte d'Ivoire

3. France, Guadeloupe

4. France, La Réunion

5. France, Martinique

6. France, New Caledonia

7. French Guyana

8. French Polynesia

9. Gaza Strip and West Bank

10. Korea, Democratic Republic of

11. Korea, Republic of

12. Maldives

13. Montenegro

14. Republic of Moldova

15. Saint Lucia

16. Sao Tome and Principe

17. South Sudan

18. The former Yugoslav Republic of Macedonia

19. Timor-Leste

\section{Appendix B}

\section{List of countries excluded from the multiple linear} regression model

1. Bahrain

2. Bhutan

3. Burundi

4. Comoros

5. Congo, Democratic Republic of

6. Cuba

7. Djibouti

8. Equatorial Guinea

9. Eritrea

10. Guam

11. Libya

12. Papua New Guinea

13. Puerto Rico

14. Qatar

15. Singapore

16. Somalia

17. Swaziland

18. Syrian Arab Republic

Table 16 Modeled 25(OH) D in association with incidence of CRC >/=75 years of age, controlling for covariates

\begin{tabular}{|c|c|c|c|c|}
\hline Covariate & Regression Coefficient & Standard Error & $t$ & $p$-value \\
\hline Modeled 25(OH) D, ng/mla & -1.79 & 0.63 & -2.83 & 0.005 \\
\hline Urbanization $^{\text {b }}$ & 0.27 & 0.40 & 0.68 & 0.50 \\
\hline $\mathrm{GDP}^{\mathrm{C}}$ & 0.002 & 0.001 & 3.01 & 0.003 \\
\hline Life Expectancy ${ }^{d}$ & 0.001 & 0.007 & 0.11 & 0.91 \\
\hline Smoking ${ }^{e}$ & 1.66 & 1.01 & 1.64 & 0.10 \\
\hline Animal Consumption ${ }^{f}$ & 1.40 & 0.34 & 4.15 & $<0.001$ \\
\hline Intercept & 75.33 & 42.31 & 1.78 & 0.08 \\
\hline
\end{tabular}

Model $R^{2}=0.62 ; p<0.001 ;{ }^{a}$ Mohr S, B, Gorham E, D, Garland C, F, Grant W, B, Garland F, C: Low Ultraviolet B and Increased Risk of Brain Cancer: An Ecological Study of 175 Countries. Neuroepidemiology 2010; 35:281-290. doi: https://doi.org/10.1159/000314350. ${ }^{b}$ Christenson E et al. [22]. ${ }^{c, d}$ The World Bank. ${ }^{\text {Institute for }}$ Health Metrics and Evaluation (IHME). ${ }^{f}$ The Food and Agricultural Organization of the United Nations (FAO) 


\section{Appendix C}

List of the codes for the representation of names of countries (ISO 3166 standard)

1. AFG Afghanistan

2. AGO Angola

3. ALB Albania

4. ARE United Arab Emirates

5. ARG Argentina

6. ARM Armenia

7. ATA Antarctica

8. AUS Australia

9. AUT Austria

10. AZE Azerbaijan

11. BDI Burundi

12. BEL Belgium

13. BEN Benin

14. BFA Burkina Faso

15. BGD Bangladesh

16. BGR Bulgaria

17. BHR Bahrain

18. BHS Bahamas

19. BIH Bosnia and Herzegovina

20. BLR Belarus

21. BLZ Belize

22. BOL Bolivia

23. BRA Brazil

24. BRB Barbados

25. BRN Brunei Darussalam

26. BTN Bhutan

27. BWA Botswana

28. CAF Central African Republic

29. CAN Canada

30. CHE Switzerland

31. CHL Chile

32. CHN China

33. CMR Cameroon

34. COD Congo, Democratic Republic of the

35. COG Congo

36. COL Colombia

37. COM Comoros

38. CRI Costa Rica

39. CUB Cuba

40. CYP Cyprus

41. CZE Czechia

42. DEU Germany

43. DJI Djibouti

44. DNK Denmark

45. DOM Dominican Republic

46. DZA Algeria

47. ECU Ecuador

48. EGY Egypt

49. ERI Eritrea

50. ESP Spain
51. EST Estonia

52. ETH Ethiopia

53. FIN Finland

54. FJI Fiji

55. FRA France

56. GAB Gabon

57. GBR United Kingdom

58. GEO Georgia

59. GHA Ghana

60. GIN Guinea

61. GMB Gambia

62. GNB Guinea-Bissau

63. GNQ Equatorial Guinea

64. GRC Greece

65. GTM Guatemala

66. GUM Guam

67. GUY Guyana

68. HND Honduras

69. HRV Croatia

70. HTI Haiti

71. HUN Hungary

72. IDN Indonesia

73. IND India

74. IRL Ireland

75. IRN Iran

76. IRQ Iraq

77. ISL Iceland

78. ISR Israel

79. ITA Italy

80. JAM Jamaica

81. JOR Jordan

82. JPN Japan

83. KAZ Kazakhstan

84. KEN Kenya

85. KGZ Kyrgyzstan

86. KHM Cambodia

87. KWT Kuwait

88. LAO Laos

89. LBN Lebanon

90. LBR Liberia

91. LBY Libya

92. LKA Sri Lanka

93. LSO Lesotho

94. LTU Lithuania

95. LUX Luxembourg

96. LVA Latvia

97. MAR Morocco

98. MDG Madagascar

99. MEX Mexico

100MLI Mali

101MLT Malta

102MMR Myanmar

103MNG Mongolia

104MOZ Mozambique 
105MRT Mauritania 106MUS Mauritius 107MWI Malawi 108MYS Malaysia 109NAM Namibia 110NER Niger 111NGA Nigeria 112NIC Nicaragua 113NLD Netherlands 114NOR Norway 115NPL Nepal 116NZL New Zealand 117.OMN Oman 118PAK Pakistan 119PAN Panama 120PER Peru 121PHL Philippines 122PNG Papua New Guinea 123POL Poland 124PRI Puerto Rico 125PRT Portugal 126PRY Paraguay 127.QAT Qatar 128ROU Romania 129RUS Russian Federation 130RWA Rwanda 131SAU Saudi Arabia 132SDN Sudan 133SEN Senegal 134SGP Singapore 135SLB Solomon Islands 136SLE Sierra Leone 137SLV El Salvador 138SOM Somalia 139SRB Serbia 140SUR Suriname 141SVK Slovakia 142SVN Slovenia 143SWE Sweden 144SYR Syrian Arab Republic 145.TCD Chad 146.TGO Togo 147.THA Thailand 148.TJK Tajikistan 149.TKM Turkmenistan 150.TTO Trinidad and Tobago 151.TUN Tunisia 152.TUR Turkey 153.TZA Tanzania 154.UGA Uganda 155.UKR Ukraine 156.URY Uruguay 157.USA United States of America 158.UZB Uzbekistan
159.VEN Venezuela 160.VNM Viet Nam 161.VUT Vanuatu 162.WSM Samoa 163.YEM Yemen 164ZAF South Africa 165ZMB Zambia 166ZWE Zimbabwe

\begin{abstract}
Abbreviations
CRC: Colorectal Cancer; UVB: Ultraviolet B; DINOMIT: Disjunction, Initiation, Natural selection, Overgrowth, Metastasis, Involution, Transition; 25(OH)D: 25hydroxyvitamin D; Vitamin D status: as assessed by serum 25(OH) D concentration; VDR: Vitamin D Receptor; BMI: Body Mass Index; WHS: Women's Health Study; MEG3: Maternally expressed gene; GLOBOCAN: Global Cancer Database; NASA: National Aeronautics and Space Administration; ISCCP: International Satellite Cloud Climatology Project; GDP: Gross Domestic Product; PPP: Purchasing Power Parity; GHDx: Global Health Data Exchange; IHME: Institute for Health Metrics and Evaluation; FAO: Food and Agricultural Organization of the United Nations; QGIS: Quantum Geographic Information System; Choropleth map: Areas in the map are color coded to a variable.
\end{abstract}

\section{Supplementary Information}

The online version contains supplementary material available at https://doi. org/10.1186/s12889-021-11089-w.

Additional file 1: Figure S1. Colorectal cancer crude incidence rates, 15-29 years of age, all races, both sexes, 2018.

Additional file 2: Figure S2. Colorectal cancer crude incidence rates, 30-44 years of age, all races, both sexes, 2018.

Additional file 3: Figure S3. Colorectal cancer crude incidence rates, 45-59 years of age, all races, both sexes, 2018.

Additional file 4: Figure S4. Colorectal cancer crude incidence rates, 60-74 years of age, all races, both sexes, 2018.

Additional file 5: Figure S5. Colorectal cancer crude incidence rates, $>/=75$ years of age, all races, both sexes, 2018.

Acknowledgements

None.

Authors' contributions

VP and RC jointly contributed to the formulation, drafting, completion, and approval of the final manuscript. CG and TM provided guidance for data analyses and interpretation of findings. All authors have read and approved the manuscript.

\section{Funding}

This research did not receive any specific grant from funding agencies in the public, commercial, or not-for-profit sectors.

\section{Availability of data and materials}

The following data sources (open to public access) were used to collect data for this study:

1. Colorectal cancer incidence rates: Cancer Today, Ferlay J, Ervik M, Lam F,

Colombet M, Mery L, Piñeros M, Znaor A, Soerjomataram I, Bray F (2018). Global Cancer Observatory: Cancer Today. Lyon, France: International Agency for Research on Cancer. Available from: https://gco.iarc.fr/today

2. Estimates for UVB (280-315 nm), adjusted for cloud cover and aerosols: Beckmann M, Václavík T, Manceur AM, Šprtová L, von Wehrden H, Welk E, et al. gIUV: a global UV-B radiation data set for macroecological studies. Tatem A, editor. Methods Ecol Evol [Internet]. 2014 Apr 1 [cited 2020 Apr 1];5 (4):372-83. Available from: http://doi.wiley.com/10.1111/2041-210X.12168 3. Stratospheric ozone data: Earthdata [Internet]. Available from: https:// earthdata.nasa.gov/ 
4. Data on life expectancy and GDP per capita (at purchasing power parity [PPP]): World Bank Open Data; https://data.worldbank.org/

5. Pigmentation data: Jablonski NG, Chaplin G. The evolution of human skin coloration. J Hum Evol 2000; 39:57-106; PMID:10896812; https://doi.org/10. 1006/jhev.2000.0403

6. Urbanization data: Christenson E, Elliott M, Banerjee O, Hamrick L, Bartram J. Climate-related hazards: a method for global assessment of urban and rural population exposure to cyclones, droughts, and floods. Int J Environ Res Public Health. 2014;11 (2):2169-2192.

7. Smoking prevalence: Institute for Health Metrics and Evaluation (IHME). Global Smoking Prevalence and Cigarette Consumption 1980-2012. Seattle, United States: Institute for Health Metrics and Evaluation (IHME), 2014. 8. Data on animal meat consumption: The Food and Agricultural Organization of the United Nations. http://www.fao.org/faostat/en/\#data/FBS. The datasets used and/or analyzed during the current study can be accessed on GitHub repository https://github.com/ghpi2021/vitD_age

\section{Declarations}

\section{Ethics approval and consent to participate}

Not applicable.

\section{Consent for publication}

Not applicable. Data were not collected for individuals, but rather as aggregated statistics from publicly available data sources.

\section{Competing interests}

TM is a senior editorial board member of BMC Public Health. TM is an employee of the startup company S-3 Research LLC. S-3 Research is a startup funded and currently supported by the National Institutes of Health - National Institute on Drug Abuse through a Small Business Innovation and Research contract for opioid-related social media research and technology commercialization. Author reports no other conflict of interest associated with this manuscript.

\section{Author details}

'Department of Anesthesiology, University of California, San Diego, USA. ${ }^{2}$ Global Health Policy Institute, San Diego, USA. ${ }^{3}$ Division of Extended Studies, University of California, San Diego, USA. ${ }^{4}$ Department of Family Medicine and Public Health, University of California, San Diego, USA.

\section{Received: 21 October 2020 Accepted: 18 May 2021}

\section{Published online: 05 July 2021}

\section{References}

1. Ferlay J, Ervik M, Lam F, Colombet M, Mery L, Piñeros M, Znaor A, Soerjomataram I, Bray F. Global Cancer observatory: Cancer Today. Lyon: International Agency for Research on Cancer; 2018. Available from: https:// gco.iarc.fr/today. Accessed 3 May 2019.

2. Ferlay J, Soerjomataram I, Dikshit R, Eser S, Mathers C, Rebelo M, et al. Cancer incidence and mortality worldwide: Sources, methods and major patterns in GLOBOCAN 2012. Int J Cancer. 2015;136(5):E359-86 Available from: http://www.ncbi.nlm.nih.gov/pubmed/25220842. [cited 2019 May 2].

3. Bishehsari F, Mahdavinia M, Vacca M, Malekzadeh R, Mariani-Costantini R. Epidemiological transition of colorectal cancer in developing countries: Environmental factors, molecular pathways, and opportunities for prevention. World J Gastroenterol. 2014;20(20):6055 Available from: http:// www.wjgnet.com/1007-9327/full/v20/i20/6055.htm. [cited 2019 May 2].

4. Gorham ED, Garland CF, Garland FC, Grant WB, Mohr SB, Lipkin M, et al. Vitamin D and prevention of colorectal cancer. J Steroid Biochem Mol Biol. 2005;97(1-2):179-94 Available from: https://www.sciencedirect.com/ science/article/abs/pii/S0960076005002451?via\%3Dihub. [cited 2019 May 3].

5. Mohr SB, Gorham ED, Kim J, Hofflich H, Cuomo RE. Garland CF. Could vitamin D sufficiency improve the survival of colorectal cancer patients? J Steroid Biochem Mol Biol. 2015;148:239-44 Available from: https://www. sciencedirect.com/science/article/abs/pii/S0960076014003161?via\%3Dihub. [cited 2019 May 3].

6. Vitamin D - Fact sheet for Health Professionals $(\mathrm{NIH})$.

7. Garland CF, French CB, Baggerly LL, Heaney RP. Vitamin D supplement doses and serum 25-hydroxyvitamin $D$ in the range associated with cancer prevention. Anticancer Res. 2011;31(2):607-11 Available from: http://www. ncbi.nlm.nih.gov/pubmed/21378345. [cited 2019 May 3].

8. Bogh MKB, Schmedes AV, Philipsen PA, Thieden E, Wulf HC. Vitamin D Production after UVB Exposure Depends on Baseline Vitamin D and Total Cholesterol but Not on Skin Pigmentation. J Invest Dermatol. 2010;130(2): 546-53 Available from: https://www.sciencedirect.com/science/article/pii/ S0022202X15347035. [cited 2019 May 3].

9. Ekwaru JP, Zwicker JD, Holick MF, Giovannucci E, Veugelers PJ. The Importance of Body Weight for the Dose Response Relationship of Oral Vitamin D Supplementation and Serum 25-Hydroxyvitamin D in Healthy Volunteers. PLoS One. 2014;9(11):e111265 Available from: http://dx.plos. org/10.1371/journal.pone.0111265. [cited 2019 May 3].

10. Huebbe P, Nebel A, Siegert S, Moehring J, Boesch-Saadatmandi C, Most E, et al. APOE $\varepsilon 4$ is associated with higher vitamin D levels in targeted replacement mice and humans. FASEB J. 2011;25(9):3262-70 Available from: http://www.ncbi.nlm.nih.gov/pubmed/21659554. [cited 2020 Apr 1].

11. Savoie MB, Paciorek A, Zhang L, Van Blarigan EL, Sommovilla N, Abrams D, et al. Vitamin D Levels in Patients with Colorectal Cancer Before and After Treatment Initiation. J Gastrointest Cancer. 2018; Available from: http://www. ncbi.nlm.nih.gov/pubmed/30058032. [cited 2019 May 3].

12. Maalmi $H$, Walter $V$, Jansen $L$, Boakye $D$, Schöttker B, Hoffmeister M, et al. Association between Blood 25-Hydroxyvitamin D Levels and Survival in Colorectal Cancer Patients: An Updated Systematic Review and MetaAnalysis. Nutrients. 2018;10(7):896 Available from: http://www.mdpi.com/2 072-6643/10/7/896. [cited 2019 May 3].

13. Grant WB. Ecological studies of the UVB-vitamin D-cancer hypothesis. Anticancer Res. 2012;32(1):223-36 Available from: http://www.ncbi.nlm.nih. gov/pubmed/22213311. [cited 2019 May 3].

14. Giovannucci E, Liu Y, Rimm EB, Hollis BW, Fuchs CS, Stampfer MJ, et al. Prospective Study of Predictors of Vitamin D Status and Cancer Incidence and Mortality in Men. JNCI J Natl Cancer Inst. 2006;98(7):451-9 Available from: http://academic.oup.com/jnci/article/98/7/451/2522019/ProspectiveStudy-of-Predictors-of-Vitamin-D. [cited 2019 May 3].

15. Dimitrakopoulou VI, Tsilidis KK, Haycock PC, Dimou NL, Al-Dabhani K, Martin RM, et al. Circulating vitamin D concentration and risk of seven cancers: Mendelian randomisation study. BMJ. 2017;359:j4761 Available from: http:// www.ncbi.nlm.nih.gov/pubmed/29089348. [cited 2019 May 3].

16. Garland CF, Gorham ED, Mohr SB, Garland FC. Vitamin D for Cancer Prevention: Global Perspective. Ann Epidemiol. 2009;19(7):468-83 Available from: https://www.sciencedirect.com/science/article/pii/S1047279709001057. [cited 2019 May 2].

17. Mousavi SE, Amini H, Heydarpour P, Amini Chermahini F, Godderis L. Air pollution, environmental chemicals, and smoking may trigger vitamin D deficiency: Evidence and potential mechanisms. Environ Int. 2019;122:67-90 Available from: https:/pubmed.ncbi.nlm.nih.gov/30509511/. [cited 2021 Apr 8].

18. Beckmann M, Václavík T, Manceur AM, Šprtová L, von Wehrden H, Welk E, et al. glUV: a global UV-B radiation data set for macroecological studies. Methods Ecol Evol. 2014;5(4):372-83 Available from: http://doi.wiley.com/1 0.1111/2041-210X.12168. [cited 2020 Apr 1].

19. Earthdata [Internet]. Available from: https://earthdata.nasa.gov/. Accessed 3 May 2019.

20. World Bank Open Data; https://data.worldbank.org/. Accessed 3 May 2019.

21. Jablonski NG, Chaplin G. The evolution of human skin coloration. J Hum Evol. 2000;39:57-106; PMID:10896812. https://doi.org/10.1006/jhev.2000.0403.

22. Christenson E, Elliott M, Banerjee O, Hamrick L, Bartram J. Climate-related hazards: a method for global assessment of urban and rural population exposure to cyclones, droughts, and floods. Int J Environ Res Public Health. 2014;11(2):2169-92. https://doi.org/10.3390/ijerph110202169.

23. Institute for Health Metrics and Evaluation (IHME). Global Smoking Prevalence and Cigarette Consumption 1980-2012. Seattle, United States: Institute for Health Metrics and Evaluation (IHME); 2014.

24. The Food and Agricultural Organization of the United Nations. http://www. fao.org/faostat/en/\#data/FBS. Accessed 3 May 2019.

25. Mohr SB, Gorham ED, Garland CF, Grant WB, Garland FC. Low Ultraviolet B and Increased Risk of Brain Cancer: An Ecological Study of 175 Countries. Neuroepidemiology. 2010;35(4):281-90 Available from: http://www.ncbi.nlm. nih.gov/pubmed/20948235. [cited 2019 Aug 6].

26. Cuomo RE, Mohr SB, Gorham ED, Garland CF. What is the relationship between ultraviolet $\mathrm{B}$ and global incidence rates of colorectal cancer? Dermatoendocrinol. 2013;5(1):181-5 Available from: http://www.ncbi.nlm. nih.gov/pubmed/24494052. [Internet]. [cited 2019 Apr 23]. 
27. Voskarides K. The "cancer-cold" hypothesis and possible extensions for the Nordic populations. Scand J Public Health. 2019;47(5):477-81. https://doi. org/10.1177/1403494819831905.

28. Hilger J, Friedel A, Herr R, Rausch T, Roos F, Wahl D, et al. A systematic review of vitamin D status in populations worldwide. Br J Nutr. 2014;111(1): 23-45. https://doi.org/10.1017/S0007114513001840.

29. Pludowski P, Grant WB, Bhattoa HP, Bayer M, Povoroznyuk V, Rudenka E, et al. Vitamin d status in central europe. Int J Endocrinol. 2014;2014:58958712. https://doi.org/10.1155/2014/589587.

30. Palacios C, Gonzalez L. Is vitamin D deficiency a major global public health problem? J Steroid Biochem Mol Biol. 2014;144 Pt A:138-45. https://doi. org/10.1016/j.jsbmb.2013.11.003.

31. Garland CF, Gorham ED. Dose-response of serum 25-hydroxyvitamin D in association with risk of colorectal cancer: A meta-analysis.

32. Heaney RP, Davies KM, Chen TC, Holick MF, Barger-Lux MJ. Human serum 25-hydroxycholecalciferol response to extended oral dosing with cholecalciferol. Am J Clin Nutr. 2003;77(1):204-10 Available from: https:/aca demic.oup.com/ajcn/article/77/1/204/4689654. [cited 2019 Aug 6].

33. Boscoe FP, Schymura MJ. Solar ultraviolet-B exposure and cancer incidence and mortality in the United States, 1993-2002. BMC Cancer. 2006;6(1):264 Available from: http://www.ncbi.n/m.nih.gov/pubmed/17096841. [cited 2019 May 3].

34. Grant WB, Garland CF. The association of solar ultraviolet B (UVB) with reducing risk of cancer: multifactorial ecologic analysis of geographic variation in age-adjusted cancer mortality rates. Anticancer Res. 26(4A): 2687-99 Available from: http://www.ncbi.nlm.nih.gov/pubmed/16886679. [cited 2019 May 3].

35. Waltz P, Chodick G. Assessment of ecological regression in the study of colon, breast, ovary, non-Hodgkin's lymphoma, or prostate cancer and residential UV. Eur J Cancer Prev. 2008;17(3):279-86 Available from: http:// www.ncbi.nlm.nih.gov/pubmed/18414201. [cited 2019 May 3].

36. Takachi R, Tsubono Y, Baba K, Inoue Phd M, Sasazuki S, Iwasaki M, et al. Japan Public Health Center-Based Prospective Study Group. Red meat intake may increase the risk of colon cancer in Japanese, a population with relatively low red meat consumption. Asia Pac J Clin Nutr. 2011;20.

37. Aune D, De Stefani E, Ronco A, Boffetta P, Deneo-Pellegrini H, Acosta G, Mendilaharsu M. Fruits, vegetables and the risk of cancer: a multisite casecontrol study in Uruguay. Asian Pac J Cancer Prev. 2009;10(3): 419-28.

38. Zhang J, Dhakal IB, Zhao Z, Li L. Trends in mortality from cancers of the breast, colon, prostate, esophagus, and stomach in East Asia: role of nutrition transition. Eur J Cancer Prev. 2012;21(5):480-9. Available from: https://journals.Iww.com/eurjcancerprev/Fulltext/2012/09000/Trends_in_ mortality_from_cancers_of_the_breast,.12.aspx. [cited 2021 Jun 1].

39. Zhang FF, Cudhea F, Shan Z, Michaud DS, Imamura F, Eom H, et al. Preventable Cancer Burden Associated With Poor Diet in the United States. JNCI Cancer Spectr. 2019;3(2):pkz034. Available from: http://www.ncbi.nlm. nih.gov/pubmed/31360907. [cited 2019 Aug 6].

40. Cheng J, Chen Y, Wang X, Wang J, Yan Z, Gong G, et al. Meta-analysis of prospective cohort studies of cigarette smoking and the incidence of colon and rectal cancers. Eur J Cancer Prev. 2015;24(1). Available from: https:// journals.Iww.com/eurjcancerprev/Fulltext/2015/01000/Meta_analysis_of_ prospective_cohort_studies_of.2.aspx. [cited 2021 Jun 1].

41. Tsoi KKF, Pau CYY, Wu WKK, Chan FKL, Griffiths S, Sung JJY. Cigaette Smoking and the Risk of Colorectal Cancer: A Meta-analysis of Prospective Cohort Studies. Clin Gastroenterol Hepatol. 2009;7(6):682-8.e5. https:// pubmed.ncbi.nlm.nih.gov/19245853/. [cited 2021 Jun 1].

42. Liang PS, Chen TY, Giovannucci E. Cigarette smoking and colorectal cance incidence and mortality: systematic review and meta-analysis. Int J Cancer. 2009;124:2406-15. Available from: www.interscience. [cited 2021 Jun 1].

43. Chandler PD, Buring JE, Manson JE, Giovannucci EL, Moorthy MV, Zhang S, et al. Circulating Vitamin D Levels and Risk of Colorectal Cancer in Women. Cancer Prev Res (Phila). 2015;8(8):675-82 Available from: http://www.ncbi. nlm.nih.gov/pubmed/25813525. [cited 2019 May 3].

44. Zhu Y, Chen P, Gao Y, Ta N, Zhang Y, Cai J, et al. MEG3 Activated by Vitamin D Inhibits Colorectal Cancer Cells Proliferation and Migration via Regulating Clusterin. EBioMedicine. 2018;30:148-57 Available from: http:// www.ncbi.nlm.nih.gov/pubmed/29628342. [cited 2019 May 3]

45. Grant WB. An estimate of premature cancer mortality in the U.S. due to inadequate doses of solar ultraviolet-B radiation. Cancer. 2002;94(6):1867-75 Available from: http://doi.wiley.com/10.1002/cncr.10427. [cited 2019 May 3].
46. Gausman V, Dornblaser D, Anand S, Hayes RB, O'Connell K, Du M, et al. Risk Factors Associated With Early-Onset Colorectal Cancer. Clin Gastroenterol Hepatol. 2019; Available from: http://www.ncbi.nlm.nih.gov/pubmed/31622 737. [cited 2020 Apr 1].

\section{Publisher's Note}

Springer Nature remains neutral with regard to jurisdictional claims in published maps and institutional affiliations.
Ready to submit your research? Choose BMC and benefit from:

- fast, convenient online submission

- thorough peer review by experienced researchers in your field

- rapid publication on acceptance

- support for research data, including large and complex data types

- gold Open Access which fosters wider collaboration and increased citations

- maximum visibility for your research: over $100 \mathrm{M}$ website views per year

At BMC, research is always in progress.

Learn more biomedcentral.com/submissions 